\title{
0 Reencape de Agulhas e Descarte de Resíduos Odontológicos do Grupo E por Estudantes de uma Universidade Pública Brasileira
}

\section{MANEJO DE AGUJAS Y DESECHE DE RESIDUOS ODONTOLOGICOS DEL GRUPO E POR ESTUDIANTES DE UNA UNIVERSIDAD PÚBLICA BRASILEÑA}

Ronald Jefferson Martins', Naiana de Melo Belila², Cléa Adas Saliba Garbin'1, Artênio José Ísper Garbin', Mayumi Domingues Kato ${ }^{3}$

1. Profesor del Programa de Postítulo en Odontología Preventiva y Social de la Facultad de Odontología de Araçatuba, Universidad Estatal Paulista.

2. Alumna del Programa de Postítulo en Odontología Preventiva y Social de la Facultad de Odontología de Araçatuba, Universidad Estatal Paulista.

3. Alumna de graduación de la Facultad de Odontologia de Araçatuba, Universidad Estatal Paulista.

\section{RESUMO}

A prática da odontologia predispõe o acadêmico a sofrer acidente com material biológico. Objetivou-se neste trabalho verificar a adesão às precauções padrão, em especial a recomendação de não reencapar agulhas, bem como o descarte de resíduos odontológicos nos recipientes do grupo E, baseado no comportamento revelado pelos estudantes de odontologia de uma universidade pública brasileira. Coletaram-se todos os recipientes de descarte utilizados no ano de 2016 nas clínicas da faculdade, os quais foram levados para sala de expurgo para análise. Inicialmente, realizou-se a separação das agulhas conforme o tipo de reencape e também de outros materiais descartados. Posteriormente, procedeu-se à contagem das agulhas colocadas sobre uma bancada forrada, com a ajuda de uma pinça longa. No total, foram analisados 111 recipientes de descarte do grupo E, com 6.729 agulhas descartadas. Destas, 1.078 (16\%) estavam reencapadas nos dois lados, 1.960 (29,1\%) em um lado e 3.691 (54,9\%) sem reencape. Além disso, foram observados diferentes materiais não perfurocortantes descartados, incluindo películas radiográficas e dentes humanos. Conclui-se que a adesão dos estudantes às precauções padrão, especialmente à recomendação de não reencapar agulhas, é baixo. Os recipientes de descarte de perfurocortantes estão sendo utilizados de maneira incorreta.

(Jefferson R, Naiana de Melo B, Saliba C, Ísper A, Domingues M, 2017. 0 Reencape de Agulhas e Descarte de Resíduos Odontológicos do Grupo E por Estudantes de uma Universidade Pública Brasileira. Cienc Trab. May-Ago; 19 [59]: 91-94).

Palavras-chave: AGULHAS, RESÍDUOS DE SERVIÇOS DE SAÚDE, RESÍDUOS ODONTOLÓGICOS.

\section{RESUMEN}

La práctica de la Odontología predispone el estudiante a accidentes con material biológico. Este estudio tuvo como objetivo verificar la adhesión de alumnos a las precauciones estándares, en especial la recomendación en el manejo de agujas, así como el deseche de residuos odontológicos en recipientes del grupo $\mathrm{E}$, basado en el comportamiento revelado por los estudiantes de odontología de una universidad pública brasileña. Se recolectaron todos los recipientes de deseche utilizados en el año de 2016 en las clínicas de la facultad, los que se llevaron para el sector de expurgo para análisis. Se separaron las agujas según el tipo de manejo y también otros materiales desechados. Se procedió el contaje de agujas sobre una bancada forrada con ayuda de una tenaza larga. En el total, se analizaron 111 recipientes de deseche del grupo E, con 6.729 agujas desechadas. De esas, 1.078 (16\%) mantenían su capuchón plástico en ambos lados, $1.960(29,1 \%)$ en solo un lado y 3.691 (54,9\%) no tenían su capuchón. Además, se observaron diferentes materiales punzocortantes desechados, entre ellos películas radiográficas y dientes humanos. Se concluye que la adhesión de los estudiantes a las precauciones estándares, en especial a la recomendación de no manejar agujas, es baja. Los recipientes de deseche de punzocortantes están siendo utilizados de manera incorrecta.

Palabras clave: AGUJAS, RESIDUOS SANITARIOS, RESIDUOS DENTALES.

\section{INTRODUCCIÓN}

A prática da odontologia predispõe o acadêmico a sofrer acidente com material biológico. ${ }^{1-3}$ Isso se deve ao contato com materiais

\section{Correspondencia / Correspondence:}

Ronald Jefferson Martins

NEPESCO - Núcleo de Pesquisa em Saúde Coletiva (Núcleo de Investigación en Salud Colectiva). Departamento de Odontología Infantil y Social, Facultad de Odontología de Araçatuba, Universidad Estatal Paulista.

R. José Bonifácio № 1193, Barrio Vila Mendonça, Araçatuba, SP.

CP $16015-050$

Tel: (55 18) 3636-3250

e-mail: rojema@foa.unesp.br

Recibido: 13 de Abril de 2017 / Aceptado: 09 de Julio de 2017 perfurocortantes, rotatórios e ultrasônicos em um campo restrito de visualização. ${ }^{4,5}$

Baseada nessa constatação foram propostas medidas preventivas a fim de minimizar ou impedir a ocorrência de infortúnios, chamadas hodiernamente de precauções padrão. As recomendações incluem considerar todos os pacientes potencialmente contaminados; a correta higienização das mãos; o uso de equipamentos de proteção individual, como luvas, máscaras, gorros, óculos de proteção, aventais (jalecos), calçados fechados e protetores faciais e auriculares; imunizações, em especial contra a hepatite B e também influenza, tríplice viral e dupla adulta; todas fornecidas gratuitamente aos trabalhadores dos serviços de saúde. .,7 $^{6,}$

Devido os acidentes percutâneos com sangue contaminado, provocados por instrumentos perfurantes e/ou cortantes, serem os que apresentam maior risco de infecção pós-exposição ocupacional por HIV e virus das hepatites B e C, o não encape ou reencape de agulhas 
é outra importantíssima medida preconizada pelas precauções padrão. $^{6-8}$ Todavia, este comportamento individual de risco é frequentemente observado entre os futuros profissionais da odontologia. ${ }^{3,9}$

Verifica-se também o descarte de materiais perfurocortantes em locais inadequados ou recipientes superlotados. ${ }^{10,11}$ Os Resíduos do Serviço de Saúde (RSS) do Grupo E que compreendem os materiais perfurocortantes ou escarificantes, capazes de cortar ou perfurar, como lâminas de bisturi, agulhas, ampolas de anestésico de vidro, brocas, limas endodônticas, pontas diamantadas, entre outros; devem ser descartados em recipientes de paredes rígidas até a capacidade útil do coletor., ${ }^{9,12}$

Outras práticas observadas são o transporte ou manipulação de agulhas desprotegidas e a desconexão da agulha da seringa. ${ }^{10,11}$

No Brasil, a Norma Regulamentadora 32 (NR 32) estabelece as diretrizes básicas para implementação de medidas que visam proteção à segurança e à saúde dos trabalhadores dos serviços de saúde. 0 item 32.2.4.15 da referida norma afirma ser vedado o reencape e a desconexão manual de agulhas., ${ }^{713}$

Poucos estudos buscaram verificar de forma objetiva a prática do reencape; por este motivo, procurou-se analisar nesta pesquisa a adesão às precauções padrão, em especial a recomendação de não reencapar agulhas, bem como o descarte de resíduos odontológicos nos recipientes do grupo $\mathrm{E}$, baseado no comportamento revelado pelos estudantes de odontologia de uma universidade pública brasileira.

\section{MATERIAL Y MÉTODO}

A pesquisa configura-se como um estudo descritivo, de caráter transversal, com uma abordagem quantitativa. 0 universo da pesquisa foi composto por todos recipientes de descarte de objetos perfurocortantes das clínicas da Faculdade de Odontologia de Araçatuba, Universidade Estadual Paulista, Brasil, utilizados no ano de 2016.

Os recipientes do tipo "Descarpak" de capacidade total de 3,0 litros e útil de 2,3 litros foram transportados para a sala de expurgo da faculdade e seus conteúdos depositados sobre uma mesa forrada. 0 pesquisador utilizou todos os Equipamentos de Proteção Individual (EPIs) indicados para o experimento; como luvas de borracha grossa, jaleco de manga longa e óculos de proteção.

Inicialmente, as agulhas foram separadas uma a uma conforme o tipo de reencape e de outros materiais descartados com a ajuda de uma pinça longa. Posteriormente, realizou-se a contagem das agulhas e análise dos materiais descartados, retornando o conteúdo para o mesmo recipiente no final, que foi lacrado e colocado em um saco para posteriormente ser recolhido pela empresa responsável.

Os dados coletados foram tabulados por meio do programa Epi InfoTM 7 e apresentados em frequências absolutas e percentuais.

\section{RESULTADOS}

No total, coletaram-se 111 recipientes de descarte de perfurocortantes. Não foram encontrados recipientes superlotados (acima da linha indicativa do recipiente), ou seja, acima da capacidade útil do recipiente. Os mesmos estavam localizados em um suporte na parede atrás da cadeira odontológica e eram do tipo "Descarpak". Nos recipientes haviam 6.729 agulhas descartadas. Destas, 1.078 (16\%) estavam reencapadas nos dois lados, 1.960 (29,1\%) em um lado e 3.691 (54,9\%) sem reencape.

Observaram-se diferentes matérias não perfurocortantes descartados erroneamente; como radiografias, dentes humanos, medicamentos em comprimidos, tubetes anestésicos, sugador plástico, goma de mascar, elemento protético provisório, copo plástico, espátulas de madeira, algodão, gaze, papel toalha, embalagem de fio de sutura, papel carbono, fio dental, luvas de procedimento, lixa de polimento de resina, material de moldagem, máscara cirúrgica, hastes de algodão, prendedores de papel (clips) e fitas crepe e adesiva.

\section{DISCUSIÓN}

Na Odontologia, os estudantes sofrem grande número de acidentes com materiais perfurocortantes. ${ }^{1-3}$ Estudo mostra que esta população apresenta maior probabilidade de infortúnios, quando comparada a estudantes de outras áreas da saúde, devido à ausência de experiência clínica e pouca habilidade no manuseio dos instrumentais odontológicos. ${ }^{14}$

A maioria das exposições ocupacionais a material biológico ocorre pela inadequada prática de encape e reencape de agulhas. ${ }^{3,10,11} \mathrm{~A}$ não adoção de medidas preventivas que visam evitar acidentes, ou seja, a realização de comportamentos de risco, pode ser explicada por fatores individuais (crenças), organizacionais, ou relativos ao trabalho. ${ }^{15,16}$

No presente estudo, observou-se alta porcentagem de agulhas reencapadas em um lado, ou em ambos os lados. Pode-se imaginar que o duplo reencape (nos dois lados) acabe por dobrar o risco da ocorrência de acidentes. Essa prática sugere uma preocupação em proteger os outros indivíduos em detrimento da própria segurança do aluno. ${ }^{10,17}$

$\mathrm{Na}$ prática odontológica é utilizada a seringa carpule para a dessensibilização. Muitas vezes a anestesia precisa ser complementada, predispondo os alunos a acidentes por deixarem a agulha exposta sobre a bancada, ou reencapá-la. ${ }^{10,11}$ Além disso, ao final do procedimento, a agulha precisa ser destacada da seringa para posterior descarte em recipiente adequado.

0 anexo III da Norma Regulamentadora 32 (NR-32) de Segurança e Saúde no Trabalho em Serviços de Saúde afirma que os estabelecimentos de saúde devem adotar medidas de controle para a prevenção de acidentes com materiais perfurocortantes. Entre essas medidas está o uso de materiais com dispositivo de segurança integrado a um conjunto do qual faça parte o elemento perfurocortante ou uma tecnologia capaz de reduzir o risco de acidente. ${ }^{18}$ Em especial para a odontologia, existem no mercado materiais com dispositivos de segurança que podem minimizar ou evitar a ocorrência de acidentes com agulhas. Entre eles podem ser citados recipientes de descarte de perfurocortantes com dispositivo para remoção de agulhas; dispositivos para remoção do protetor ou da agulha da seringa; suportes para descanso da seringa na bancada e sistemas para encape e reencape de agulhas; seringas com sistema que facilita a eliminação da agulha no recipiente de descarte (No-touch system); dispositivo contra perfurações nos dedos; entre outros. ${ }^{7}$

As empresas que manufaturam ou comercializam materiais perfurocortantes deverão disponibilizar para os trabalhadores dos 
serviços de saúde a correta capacitação para a utilização do dispositivo de segurança. Posteriormente, é necessário realizar uma análise do desempenho do material com dispositivo de segurança, a fim de verificar se houve a diminuição dos acidentes com perfurocortantes e da efetividade do uso do produto, para decisão de qual material deverá ser adotado pelos profissionais., ${ }^{7,18}$

Em um trabalho de revisão da literatura dos trabalhos publicados no período de 2001 a maio de 2011, sobre a diminuição dos acidentes devido à implementação de materiais com dispositivos de segurança, observou-se uma significativa redução dos acidentes com materiais perfurocortantes. Entre os trabalhos analisados, não havia nenhum brasileiro, nem na categoria de profissionais da área odontológica. ${ }^{19}$

Em outra revisão de literatura compreendendo o período de 2006 a 2014, os autores verificaram que apenas uma publicação havia mencionado aumento no número de acidentes após a implementação do uso de materiais com dispositivo de segurança, devido a falhas no mecanismo de segurança, inesperiência e desconhecimento dos trabalhadores quanto ao uso da tecnologia. A maioria dos autores afirmou que o uso de instrumentos perfurocortantes com dispositivo de segurança garante a redução de acidentes com material biológico. ${ }^{20}$

Verificou-se no presente trabalho o descarte de materiais não perfurocortantes nos recipientes do Grupo E da faculdade. Acreditamos que o aluno aproveite o momento de descarte do material perfurocortante para também descartar outros materiais. Entre estes materiais, pode ser destacada a película radiográfica periapical, que pode ir parar em aterros sanitários e contaminar o solo e lençol freático, devido à prata que é um metal pesado altamente poluente e prejudicial à saúde. Por esta razãpo, as películas deverão ser encaminhadas a empresas específicas para recuperação da prata. ${ }^{12}$

Outra observação foi a presença de dentes humanos descartados, que pode causar poluição biológica. Os dentes extraídos devem ser vistos pelos profissionais da odontologia e pela população como órgãos do corpo humano. É indicada a sua descontaminação e acondicionamento em um banco de dentes para posteriormente serem reaproveitados nas universidades. ${ }^{21,22}$

Salienta-se também o incorreto descarte de medicamentos, que pode levar a contaminação da água e efeitos adversos para a saúde humana, animal e de organismos aquáticos, devendo serem entregues em locais autorizados; como postos de saúde ou vigilâncias municipais. ${ }^{23,24}$ Os demais materiais não perfurocortantes descartados mostram a negligência da finalidade do recipiente, levando a diminuição da vida útil do mesmo e consequente aumento do gasto da faculdade devido a necessidade da compra de novas embalagens. ${ }^{9}$

A universidade deve apresentar maior envolvimento na implementação, acompanhamento e difusão de protocolos de biossegurança que possibilitem a conscientização e adesão das condutas preventivas contra exposições a material biológico, além do correto descarte de resíduos dos serviços de saúde. Esses assuntos deverão ser trabalhados no decorrer do curso de odontologia, com o propósito de minimizar os riscos no processo ensino aprendizagem dos alunos. ${ }^{25,26}$

Ainda, deve ser proporcionado um ambiente seguro que inclua, como medida preventiva, o uso rotineiro de materiais com dispositivo de segurança, após a realização de estudos que analisem a eficácia dos referidos materiais, revelada pela diminuição dos infortúnios ocupacionais. $^{18,25}$

Reafirma-se o papel fundamental da universidade na formação de futuros profissionais de saúde mais conscientes dos riscos e medidas de prevenção e controle de doenças e do professor como orientador de práticas seguras, pois para o aluno ele é um modelo a ser seguido. ${ }^{25}$

Um espaço necessita ser aberto para a discussão com os acadêmicos de odontologia a respeito das dificuldades para adotar medidas preventivas, ou quais fatores estão influenciando para o seu comportamento de risco. ${ }^{11}$

Espera-se que os resultados encontrados neste trabalho possam orientar estratégias de intervenção capazes de motivar os graduandos de odontologia a adotar as precauções padrão.

\section{CONCLUSIÓN}

Conclui-se que a adesão dos estudantes às precauções padrão, especialmente à recomendação de não reencapar agulhas, é baixo. Os recipientes de descarte de perfurocortantes estão sendo utilizados de maneira incorreta. 


\section{REFERENCIAS}

1. Smith WA, Al-Bayaty HF, Matthews RW. Percutaneous injuries of dental personnel at the University of the West Indies, School of Dentistry. Int Dent J. 2006; 56(4):209-214.

2. Rico RD, Loya ML, Sanin LH, López SR. Accidentes por objetos punzocortantes en estudiantes de una escuela de odontología. Cienc Trab. 2006; 8(21):131-134.

3. Garbin CAS, Martins, RJ, Garbin AJi, Hidalgo LRC. Conductas de estudiantes del área de la salud frente a la exposición ocupacional a material biológico. Cienc Trab. 2009; 11(31):18-21.

4. Garcia LP, Blank VLG. Prevalência de exposições ocupacionais de cirurgiõesdentistas e auxiliares de consultório dentário a material biológico. Cad Saúde Pública. 2006; 22(1):97-108.

5. Garcia LP, Blank VLG. Condutas pós-exposição ocupacional a material biológico na odontologia. Rev Saúde Pública. 2008; 42(2):279-286.

6. Garner JS. Hospital Infection Control Practices Advisory Committee. Guideline for isolation precautions in hospitals. Infect Control Hosp Epidemiol. 1996; 17(5):53-80.

7. Garbin All, Martins RJ, Arcieri RM. Recomendações para minimizar ou impedir a transmissão de agentes infecciosos. In: Garbin AJl, Garbin CAS, Rovida TAS. Caminhos para uma Odontologia segura: a prática com responsabilidade. Guararapes-SP: Gráfica Moço; 2012. p.153-169.

8. Brasil. Ministério da Saúde. Secretaria de Politicas de Saúde. Coordenação Nacional de DST e Aids. Manual de condutas; Exposição ocupacional a material biológico: Hepatite e HIV. $2^{\text {a }}$ ed [on line]. Brasilia: Ministério da Saúde; 2000 [consultado 13 jan 2017]. Disponible en: http://bvsms.saude.gov.br/bvs/publicacoes/manual_condutas_hepatite_hiv.pdf

9. Martins RJ, Garbin CAS, Garbin All, Miguel N. La práctica de recapsular agujas por profesionales de la salud y condiciones de los depósitos de material cortopunzante. Cienc Trab. 2012; 14(44):185-188.

10. Brevidelli MM, Cianciarullo TI. Aplicação do modelo de crenças em saúde na prevenção dos acidentes com agulha. Rev Saúde Pública. 2001; 35(2):193-201.

11. Brevidelli MM, Cianciarullo TI. Análise dos acidentes com agulhas em um hospital universitário: situações de ocorrência e tendências. Rev Latinoam Enferm. 2002; 10(6):780-786.

12. Brasil. Ministério da Saúde. Agência Nacional de Vigilância Sanitária. Manual de gerenciamento de resíduos de serviços de saúde. Brasília: Ministério da Saúde; 2006. 182 p. (Série A: Normas e Manuais Técnicos). [consultado 13 jan 2017]. Disponible en: www.anvisa.gov.br/servicosaude/manuais/manual_gerenciamento_residuos.pdf

13. Brasil. Ministério do Trabalho e Emprego. Portaria n. 485 (11 nov 2005). Norma Regulamentadora de Segurança e Saúde no Trabalho em Estabelecimentos de
Saúde: NR 32 [on line]. Brasilia: Ministério do Trabalho e Emprego; 2006 [consultado 13 jan 2017]. Disponible en: http://www.anvisa.gov.br/servicosaude/avalia/saude_do_trabalhador_portaria_485_aprova_NR32.pdf

14. Zhang Z, Moji K, Cai G, Ikemoto J, Kuroiwa C. Risk of sharps exposure among health science students in northeast China. Biosci Trends. 2008; 2(3):105-111.

15. Martins RJ, Moimaz SAS, Sundefeld MLMM, Garbin AJI, Gonçalves, PRV, Garbin CAS. Adesão às precauções padrão sob o prisma do Modelo de Crenças em Saúde: a prática de reencapar agulhas. Cienc Saude Coletiva. 2015; 20(1):193-198.

16. Gonçalves PRV, Martins RJ, Moimaz SAS, Sundefeld MLMM, Garbin Ali, Garbin CAS. Influência dos fatores individuais, relativos ao trabalho e organizacionais na adesão às precauções padrão. R Epidemiol Control Infec. 2016; 6(2):44-49.

17. Brevidelli MM, Cianciarullo TI. Fatores psicossociais e organizacionais na adesão às precauções-padrão. Rev Saúde Pública. 2009; 43(6):907-916.

18. Brasil. Ministério do Trabalho e Emprego. Port No.1.748 (30 ago 2011). [consultado 13 jan 2017]. Disponible en: http://www.sindhosp.com.br/anexos/NR32/ NR_set11.pdf

19. Oliveira AC, Pinto SA, Garbaccio JL. Needle-stick stuffs with safety device for prevention of percutaneous injuries: a literature review. J Nurs UFPE. 2012; 6(11):2830-2838.

20. Sper NPT, Mauro MYC, Gomes ICM. Dispositivos de segurança em instrumentos perfurocortantes versus acidentes com exposição a material biológico. Rev enferm UERJ. 2015; 23(6):845-851.

21. Sponchialo Junior $E C$, Guimarães $C C$, Marques $A A F$, Rebelo MAB, Conde NCO, Bandeira MFCL. Banco de dentes humanos e educação em saúde na Universidade Federal do Amazonas. Relato de experiência. Abeno. 2012; 12(2):185-189.

22. Miranda GE, Bueno FC. Banco de dentes humanos: uma análise bioética. Rev bioét. 2012; 20(2):255-266.

23. Falqueto $E$, Kligerman DC, Assumpção RF. Como realizar o correto descarte de resíduos de medicamentos? Cien Saúde Colet. 2010; 15(2):3283-3293.

24. Medeiros MSG, Moreira LMF, Lopes CCGO. Descarte de medicamentos: programas de recolhimento e novos desafios. Rev Ciênc Farm Básica Apl. 2014; 35(4):651-662.

25. Lima LKOL, Tipple AFV, Barros DX, Ferreira OS, Paiva EMM, Simões LLP. Acidentes com material biológico entre estudantes de Odontologia no Estado de Goiás e o papel das instituições de ensino. Rev Odontol Bras Central. 2012; 21(58):553-559.

26. Lages SMR, Santos AF, Silva Junior FF, Costa JG. Formação em Odontologia: 0 papel das instituições de ensino na prevenção do acidente com exposição a material biológico. Cienc Trab. 2015; 17(54):182-187. 